\title{
Stenosis of the Subglottic Trachea Revealing Relapsing Polychondritis of a Young Adult
}

\author{
Mounira El Euch, Madiha Mahfoudhi*, Imen Gorsane, Souha Hadded, Wifek Bani, \\ Moez Karoui, Sami Turki, Taieb Ben Abdallah \\ Department of Internal Medicine A, Charles Nicolle Hospital, Tunis, Tunisia \\ Email: ${ }^{*}$ madiha mahfoudhi@yahoo.fr
}

Received 18 April 2015; accepted 14 September 2015; published 17 September 2015

Copyright (C) 2015 by authors and Scientific Research Publishing Inc.

This work is licensed under the Creative Commons Attribution International License (CC BY). http://creativecommons.org/licenses/by/4.0/

c) (i) Open Access

\begin{abstract}
Relapsing polychondritis is a rare inflammatory disease involving essentially cartilaginous structures. Other systemic manifestations can be encountered as the eye and ear disturbance. Aortic aneurysms affect few cases. If affection of airway cartilages occurs, prognosis may be worsened by eventual stenotic lesions. We report a 22-year-old woman with Relapsing polychondritis. When she was referred to our hospital 4 weeks after the onset of respiratory symptoms, she was having severe breathing difficulty. Immediate tracheostomy followed by steroid therapy improved her respiratory condition, although the treatment was complicated because of her diabetes. While airway involvement of Relapsing polychondritis can be life threatening, it is curable with steroid therapy. Clinicians should keep in mind that airway obstruction could be caused by this disease.
\end{abstract}

\section{Keywords}

Relapsing Polychondritis, Airway Narrowing, Prognosis

\section{Introduction}

Relapsing polychondritis (RP) is a disease of unknown etiology characterized by recurrent non-infectious inflammation of cartilaginous and connective tissues. It is an uncommon, chronic, and potentially life-threatening multisystem disorder in case of laryngeal and tracheobronchial disturbance. The etiology of RP is still unknown, but the pathogenetic role of the autoimmunity is suggested by frequent overlaps with various autoimmune diseases, and by the presence of autoantibody against cartilage in the serum of patients with RP [1] [2].

Clinical presentations of RP vary considerably from patient to patient, and the involvement of multiple organs has been reported. Although several reports have demonstrated the clinical signs, pathologic manifestations and

\footnotetext{
"Corresponding author.
}

How to cite this paper: El Euch, M., Mahfoudhi, M., Gorsane, I., Hadded, S., Bani, W., Karoui, M., Turki, S. and Abdallah, T.B. (2015) Stenosis of the Subglottic Trachea Revealing Relapsing Polychondritis of a Young Adult. International Journal of Clinical Medicine, 6, 646-651. http://dx.doi.org/10.4236/ijcm.2015.69086 
radiologic findings of RP, there are no specific features of RP. Therefore, it is difficult to show the diagnosis of RP [1] [2].

Although several reports have demonstrated the clinical signs, pathologic manifestations and radiologic findings of RP, there are no specific features of RP.

Therefore, it is difficult to show the diagnosis of RP. RP is clinically diagnosed; there are no specific biological or radiological signs to confirm the diagnosis.

Radiographic study of the airway is of great value in detection and evaluation of upper respiratory involvement. Airway involvements are major causes of morbidity and mortality, and they have accounted for most of the deaths due to RP. To suppress the inflammation of airway mucosa and cartilage is extremely important in the successful treatment for RP.

RP is a polymorph multisystem pathology with various manifestations, inducing thus serious and refractory damage such as trachea stenosis due to lateness in the diagnostic delay and therapeutic management. Only rapid diagnosis and efficient therapy are guarantors of improving the prognosis and avoiding sequelae.

The aim of this study is to show that RP diagnosis should be considered in case of airway narrowing. Only an early diagnosis and an adapted treatment may improve prognosis.

\section{Observation}

A 27-year-old woman presented with eight-months history of fever, productive cough, and dyspnea. A radiographic lateral view of the neck showed subglottic tracheal stenosis. A computed tomography (CT) scan of the neck also showed narrowing of the larynx (approximately $3 \mathrm{~cm}$ until the carena). An arterial blood gas test showed a pH: 7.4, $\mathrm{PaCO}_{2}: 37 \mathrm{mmHg}, \mathrm{PaO}_{2}: 60 \mathrm{mmHg}, \mathrm{SaO}_{2}: 94 \%$, and $\mathrm{HCO}_{3}: 24 \mathrm{mEq} / \mathrm{L}$ in room air. The CRP rate was $62 \mathrm{mg} / \mathrm{L}$ and ferritin was at $560 \mathrm{ng} / \mathrm{L}$. Other laboratory findings were in the normal range. The laryngeal biopsy showed a non-specific catarrhal laryngitis Computed tomography (CT) depicted diffuse bronchotracheal stenosis, which deteriorated in exhalation. The MRI revealed airway stenosis from the trachea to the lobar bronchi. She was treated with glucocorticoid without success and the intubation was indicated. Owing to potential risks of airway compromise during intubation and/or extubation and the regression of tracheal edema, she was extubated 5 days after. Tracheotomy was made with Shiley canule. Few months later, she developed bilateral anterior uveitis and left auricular chondritis treated with glucocorticoid with success. In conjunction with nasal, which was previously overlooked, RP was finally diagnosed We made a diagnosis of relapsing polychondritis (RP) based on the following criteria set by MacAdam et al. and Damiani and Levine: 1) bilateral auricular chondritis; 2) nonerosive seronegative inflammatory polyarthritis; 3) nasal chondritis; 4) ocular inflammation; 5) respiratory tract chondritis; and 6) audiovestibular damage. Administration of high-dose glucocorticoid and azathioprine resolved the symptoms and the bronchial stenosis was stabilized. She developed 6 months later diabetes treated with metformine.

\section{Discussion}

$\mathrm{RP}$ is a relapsing degenerative disease of cartilaginous tissues characterized by the involvement of multiple organs and vessels, including the nose, ears, throat, trachea, eyes, joints and cardiac valves; however, the etiology of RP is still not fully understood [1]-[3].

$\mathrm{RP}$ is a Th1-mediated disease marked by high serum levels of interferon $\gamma$, interleukin 12 and interleukin 2 . In addition, serum levels of vascular endothelial growth factor and matrix metalloproteinases-3 are high in RP and are correlated with disease activity. Auto-immune reaction can be induced by infectious

Mechanical and chemical aggressions implicating cartilaginous structure may induce the occurrence of RP. Genetic Susceptibility to RP has been also reported.

Previous studies have suggested that autoimmunity may be associated with the pathogenesis of RP. No ethnicity, sex or age differences have been reported for RP, but most patients with RP are between 40 and 60 years of age [1] [2]. Currently, most medical practitioners and researchers apply the criteria proposed by Damiani et al. [3] for the diagnosis of RP. As RP is a rare disease with clinical manifestations that vary from patient to patient, it is very hard to diagnose, especially in patients with atypical symptoms. The early diagnosis of RP is even more challenging [1]. Laboratory investigations in this case revealed increased CRP, in accordance with previous studies [4]; interestingly, we also found an increased ferritin level, consistent with the findings of Fujiki et al. [5]. 
Airway involvement by RP is generally considered ominous and has been reported to portend a poor prognosis [6] [7]. Tracheobronchomalacia (TBM), due to loss of the supportive cartilaginous scaffolding of the upper respiratory airways, can be seen as chronic sequelae of RP due to recurrent inflammation [8]. TBM may also be the sole airway abnormality recognized during the early stages of RP. Respiratory compromise stemming from fixed airway obstruction or hyperdynamic collapse may cause significant morbidity and mortality [9]. Despite aggressive medical therapy, many patients experience symptom progression and eventually require tracheotomy, which may not be fully palliative due to frequent obstruction and malacia of more distal airways beyond the tracheotomy site [3] [10].

Lower airway manifestations of RP can be the only sign of the disease. RP has to be considered in the differential diagnosis of patients with recent onset of progressive dyspnea and severe airflow limitation even without other systemic signs of cartilage damage [9].

Unfortunately, our knowledge about airway involvement in RP is limited and is based on anecdotal reports and small case series. Purcelli et al. [11] described the first case report of RP with tracheal collapse in 1962, and McAdam et al. [8] reported in a case series in 1976 that the majority of patients with RP and a known cause of death had respiratory tract involvement. In many of those patients, airway problems were in fact the complaints leading to the diagnosis of RP, underscoring the fact that clinically significant airway compromise does not necessarily present late in the course of the disease. The majority of patients with respiratory symptoms who were referred for airway evaluation were women (70\%) like our case, a finding that differs from those in some reports that have described an equal gender distribution in patients with a clinical diagnosis of RP as a whole but is similar to those in other reports in the literature [10].

$\mathrm{RP}$ is a disorder that has a variety of clinical manifestations and is considered an autoimmune disease resulting in cartilage breakdown. In this case, the patient demonstrated severe airway stenosis on CT that was well correlated with her severe respiratory symptoms. The most common causes of death among patients with RP are infection, airway compromise, and cardiac complications [12].

Symptomatic tracheobronchial involvement implies a poor prognosis. Laryngotracheal symptoms are present in approximately $25 \%$ of the patients in the initial course of the disease, however, airway symptoms eventually occur in 50\% of all patients with RP [13]. The disorder causes airway obstruction by two mechanisms. The first is a stricture due to inflammatory swelling or scar formation in the glottic and subglottic areas. The second is dynamic airway collapse during respiration due to destruction of tracheal cartilage [14]. Accordingly, radiographic and bronchoscopic examinations may provide incorrect information for determining the degree of tracheal obstruction, as dynamic airway collapse occurs during respiration [15].

A review of few series of patients with RP illustrates the frequency of airway involvement and the female predominance (Table 1$)$.

The CT findings in patients with RP consisted mainly of airway wall thickening, airway stenosis, airway malacia, airway wall calcification, and air trapping. The most common CT manifestations were increased attenuation and smooth corticosteroid sickening of airway walls. Tracheal or bronchial stenosis was less common. Airway collapse and lobar air trapping were seen in half of patients examined with expiratory CT [9].

The utility of fluorodeoxyglucose positron emission tomography/computed tomography for early diagnosis and evaluation of disease activity of RP was reported by Yamashita et al. It seems to be a potentially powerful tool for the early diagnosis of RP, especially in patients without easily biopsied organ involvement [21]. Respiratory function test is sensitive in early detection of airway involvement in RP. Bronchoscopy and CT are useful

Table 1. Review of literature of RP cases.

\begin{tabular}{|c|c|c|c|c|c|c|}
\hline Author & $\mathrm{n}$ & Period & Age & Female & $\begin{array}{c}\text { Airway } \\
\text { involvement }\end{array}$ & Deaths \\
\hline Gao L et al. [16] & 23 & 1996-2011 & - & - & 10 & 3 \\
\hline Hong G et al. [17] & 12 & 2004-2011 & 48 & 5 & 12 & 9 \\
\hline Zhang JQ et al. [18] & 13 & 2000-2006 & 50 & 4 & 12 & 1 \\
\hline Shi XH et al. [19] & 56 & 2006 & 45 & 18 & 38 & \\
\hline Maimon N et al. [20] & 3 & 1995-2007 & 44 & 3 & 3 & 2 \\
\hline
\end{tabular}


in evaluation of the severity of airway involvement in patients with RP.

In this case, subglottic stenosis was found during a bronchoscopic examination and emergency tracheostomy was performed. Other chondritis and bilateral scleritis developed 3 months after tracheostomy. Chang et al. described the same features leading to tracheostomy but the patient's upper airway was completely collapsed [22]. In fact, tracheostomy was once the most likely surgical procedure in RP. However, this procedure is only effective in patients with upper subglottic involvement. In cases of extensive tracheobronchial involvement, tracheostomy is ineffective because the distant tracheal collapse below the tracheostomy is still unresolved [23].

There are a number of treatments available for RP. Immunosuppression including steroid medication and chemotherapy with drugs is considered the primary option. A tracheostomy or surgical interventions, such as airway stenting, are indicated for patients with aggravated tracheobronchial symptoms like our patient. Airway management such as laryngotracheal reconstruction can improve quality of life and palliate patients effectively [24].

Corticosteroids remain the major treatment. Other therapies include nonsteroidal anti-inflammatory drugs, dapsone, colchicine, azathioprine, methotrexate, cyclophosphamide, hydroxychloroquine, cyclosporine, and infliximab [25]. Corticosteroid therapy is effective in improving the symptoms and delaying the progression of relapsing polychondritis with involvement of the respiratory tract at early stage. At later stage of the disease, airway interventional therapy, such as metallic stent placement, tracheostomy or positive airway pressure support, can be used to treat airway obstruction and to improve the survival. The successful use of infliximab is reported by some authors [26].

The airway tract involvement is known to be one of the most important prognostic factors in patients with RP [27]. The possibility that airway obstruction in the initial stages of RP is due to airway inflammation and that early, aggressive immunosuppressive treatment of RP may delay or prevent irreversible cartilaginous destruction and airway collapse is discussed [28].

This case is reported with the hope of increasing awareness about the potential for early upper airway involvement in RP [23] [29]-[35].

\section{Conclusion}

Symptomatic airway involvement in patients with RP is common, diverse, has a female predominance, and may occur throughout the course of disease. Dynamic CT scans are useful tools for the detection and surveillance of airway involvement in this population. The treatment of airway problems encountered in patients with RP can be challenging and needs to be individualized. Therefore, accurate diagnosis and referral to a specialized center for full multidisciplinary workup, medical treatment, and possible endoscopic intervention are important.

\section{Conflict of Interest}

There are no conflicts of interest.

\section{References}

[1] Sharma, A., Gnanapandithan, K., Sharma, K. and Sharma, S. (2013) Relapsing Polychondritis: A Review. Clinical Rheumatology, 32, 1575-1583. http://dx.doi.org/10.1007/s10067-013-2328-x

[2] Chopra, R., Chaudhary, N. and Kay, J. (2013) Relapsing Polychondritis. Rheumatic Disease Clinics of North America, 39, 263-276. http://dx.doi.org/10.1016/j.rdc.2013.03.002

[3] Damiani, J.M. and Levine, H.L. (1979) Relapsing Polychondritis—Report of Ten Cases. Laryngoscope, 89, 929-946. http://dx.doi.org/10.1288/00005537-197906000-00009

[4] Keidel, S., McColl, A. and Edmonds, S. (2011) Sweet’s Syndrome after Adalimumab Therapy for Refractory Relapsing Polychondritis. BMJ Case Rep, 2011.

[5] Fujiki, F., Tsuboi, Y., Hashimoto, K., Nakajima, M. and Yamada, T. (2004) Nonherpetic Limbic Encephalitis Associated with Relapsing Polychondritis. Journal of Neurology, Neurosurgery \& Psychiatry, 75, 1646-1647. http://dx.doi.org/10.1136/jnnp.2003.035170

[6] Yi, H. and Dong, M. (2014) Clinical Analysis of 26 Patients with Relapsing Polychondritis. Lin Chuang Er Bi Yan Hou Tou Jing Wai Ke Za Zhi, 28, 446-449.

[7] Lee, K.S., Ernst, A., Trentham, D.E., Lunn, W., Feller-Kopman, D.J. and Boiselle, P.M. (2006) Prevalence of Functional Airway Abnormalities in Relapsing Polychondritis. Radiology, 240, 565-573. 
http://dx.doi.org/10.1148/radiol.2401050562

[8] McAdam, L.P., O’Hanlan, M.A., Bluestone, R. and Pearson, C.M. (1976) Relapsing Polychondritis: Prospective Study of 23 Patients and a Review of the Literature. Medicine (Baltimore), 55, 193-215. http://dx.doi.org/10.1097/00005792-197605000-00001

[9] Behar, J.V., Choi, Y.W., Hartman, T.A., Allen, N.B. and McAdams, H.P. (2002) Relapsing Polychondritis Affecting the Lower Respiratory Tract. American Journal of Roentgenology, 178, 173-177. http://dx.doi.org/10.2214/ajr.178.1.1780173

[10] Eng, J. and Sabanathan, S. (1991) Airway Complications in Relapsing Polychondritis. The Annals of Thoracic Surgery, 51, 686-692. http://dx.doi.org/10.1016/0003-4975(91)90348-T

[11] Purcelli, F.M., Nahum, A. and Monell, C. (1962) Relapsing Polychondritis with Tracheal Collapse. Annals of Otology, Rhinology \& Laryngology, 71, 1120-1129. http://dx.doi.org/10.1177/000348946207100426

[12] Michet Jr., C.J., McKenna, C.H., Luthra, H.S. and O’Fallon, W.M. (1986) Relapsing Polychondritis. Survival and Predictive Role of Early Disease Manifestations. Annals of Internal Medicine, 104, 74-78. http://dx.doi.org/10.7326/0003-4819-104-1-74

[13] Hayward, A.W. and Al-Shaikh, B. (1988) Relapsing Polychondritis and the Anaesthetist. Anaesthesia, 43, $573-577$. http://dx.doi.org/10.1111/j.1365-2044.1988.tb06692.x

[14] Krell, W.S., Staats, B.A. and Hyatt, R.E. (1986) Pulmonary Function in Relapsing Polychondritis. American Review of Respiratory Disease, 133, 1120-1123.

[15] Burgess, F.W., Whitlock, W., Davis, M.J. and Patane, P.S. (1990) Anesthetic Implications of Relapsing Polychondritis: A Case Report. Anesthesiology, 73, 570-572. http://dx.doi.org/10.1097/00000542-199009000-00037

[16] Gao, L., Lou, W.H. and Cheng, X.L. (2012) Clinical Observation of Relapsing Polychondritis: A Report of 23 Patients. Chinese Medical Journal, 92, 1126-1128.

[17] Hong, G. and Kim, H. (2013) Clinical Characteristics and Treatment Outcomes of Patients with Relapsing Polychondritis with Airway Involvement. Clinical Rheumatology, 32, 1329-1335. http://dx.doi.org/10.1007/s10067-013-2279-2

[18] Lin, Z.Q., Xu, J.R., Chen, J.J., Hua, X.L., Zhang, K.B. and Guan, Y.J. (2010) Pulmonary CT Findings in Relapsing Polychondritis. Acta Radiologica, 51, 522-526. http://dx.doi.org/10.3109/02841851003682036

[19] Shi, X.H., Tong, S.Q., Su, J.M., Huang, H., Zhang, F.C. and Tang, F.L. (2006) Characteristics of Airway Involvement in Relapsing Polychondritis. Chinese Medical Journal, 86, 1048-1051.

[20] Maimon, N., Lee, P., Paul, N., Hwang, D., Marras, T.K., Keshavjee, S., et al. (2010) Tracheobronchial Involvement as a Sole Manifestation of Relapsing Polychondritis. Journal of Bronchology \& Interventional Pulmonology, 17, 5-10. http://dx.doi.org/10.1097/LBR.0b013e3181ca27bf

[21] Yamashita, H., Takahashi, H., Kubota, K., Ueda, Y., Ozaki, T., Yorifuji, H., et al. (2014) Utility of Fluorodeoxyglucose Positron Emission Tomography/Computed Tomography for Early Diagnosis and Evaluation of Disease Activity of Relapsing Polychondritis: A Case Series and Literature Review. Rheumatology, 53, 1482-1490. http://dx.doi.org/10.1093/rheumatology/keu147

[22] Chang, S.J., Lu, C.C., Chung, Y.M., Lee, S.S., Chou, C.T. and Huang, D.F. (2005) Laryngotracheal Involvement as the Initial Manifestation of Relapsing Polychondritis. Journal of the Chinese Medical Association, 68, 279-282. http://dx.doi.org/10.1016/S1726-4901(09)70151-0

[23] Tso, A.S., Chung, H.S., Wu, C.Y., Li, J.Y., Hong, C.L., Yang, M.W., et al. (2001) Anesthetic Management of a Patient with Relapsing Polychondritis-A Case Report. Acta Anaesthesiologica Sinica, 39, 189-194.

[24] Karaman, E., Duman, C., Cansz, H., Ylmaz, M. and Ibrahimov, M. (2010) Laryngotracheal Reconstruction at Relapsing Polychondritis. Journal of Craniofacial Surgery, 21, 211-212. http://dx.doi.org/10.1097/SCS.0b013e3181c50f7d

[25] Rapini, R.P. and Warner, N.B. (2006) Relapsing Polychondritis. Clinics in Dermatology, 24, 482-485. http://dx.doi.org/10.1016/j.clindermatol.2006.07.018

[26] Cazabon, S., Over, K. and Butcher, J. (2005) The Successful Use of Infliximab in Resistant Relapsing Polychondritis and Associated Scleritis. Eye, 19, 222-224. http://dx.doi.org/10.1038/sj.eye.6701457

[27] Xie, C., Shah, N., Shah, P.L. and Sandhu, G. (2013) Laryngotracheal Reconstruction for Relapsing Polychondritis: Case Report and Review of the Literature. The Journal of Laryngology \& Otology, 127, 932-935. http://dx.doi.org/10.1017/s0022215113001746

[28] Segel, M.J., Godfrey, S. and Berkman, N. (2004) Relapsing Polychondritis: Reversible Airway Obstruction Is Not Always Asthma. Mayo Clinic Proceedings, 79, 407-409. http://dx.doi.org/10.4065/79.3.407 
[29] Eksombatchai, D., Boonsarngsuk, V., Amornputtisathaporn, N., Suwatanapongched, T. and Kurimoto, N. (2013) Tracheobronchial Involvement in Relapsing Polychondritis Diagnosed on Endobronchial Ultrasound. Internal Medicine, 52, 801-805. http://dx.doi.org/10.2169/internalmedicine.52.9416

[30] Hellmich, B., Hering, S., Duchna, H.W., Schultze-Werninghaus, G., Freitag, L., Schatz, H., et al. (2003) Airway Manifestations of Relapsing Polychondritis: Treatment with Cyclophosphamide and Placement of Bronchial Stents. Zeitschrift für Rheumatologie, 62, 73-79. http://dx.doi.org/10.1007/s00393-003-0419-9

[31] Tsunezuka, Y., Sato, H. and Shimizu, H. (2000) Tracheobronchial Involvement in Relapsing Polychondritis. Respiration, 67, 320-322. http://dx.doi.org/10.1159/000029518

[32] Sakata, A., Nakahara, H. and Murofushi, T. (2006) A Case of Severe Dyspnea Caused by Relapsing Polychondritis. Auris Nasus Larynx, 33, 215-218. http://dx.doi.org/10.1016/j.anl.2005.11.008

[33] Zhang, J.Q., Li, Q., Bai, C., Huang, Y., Dong, Y.C., Yao, X.P., et al. (2007) Clinical Features and Treatment of Relapsing Polychondritis with Involvement of the Respiratory Tract-Report of Thirteen Cases. Chinese Journal of Tuberculosis and Respiratory Diseases, 30, 173-177.

[34] Kim, I.K., Kim, M.S., Choi, Y.S. and Shin, Y.S. (2012) Anesthetic Experience of a Patient with Relapsing Polychondritis-A Case Report. Korean Journal of Anesthesiology, 63, 465-468. http://dx.doi.org/10.4097/kjae.2012.63.5.465

[35] Azuma, N. (2012) Airway Involvement in Relapsing Polychondritis. Nihon Rinsho Meneki Gakkai Kaishi, 35, 157-167. http://dx.doi.org/10.2177/jsci.35.157 